\title{
Inequality of water consumption for hygienic and sanitary purposes in production halls
}

\author{
Edyta Dudkiewicz ${ }^{1, *}$, and Marta Laska ${ }^{1}$ \\ ${ }^{1}$ Wroclaw University of Science and Technology, Faculty of Environmental Engineering, \\ Wybrzeże Wyspiańskiego 27, 50-370 Wroclaw, Poland
}

\begin{abstract}
Water consumption in hall buildings is substantial and characterised by variability over the time: yearly, seasonality, monthly, weekly, daily, hourly and second. Both, water consumption and their irregularity, influence on many processes and technical issues. Purposes for which water is consumed are various. Beyond the technological processes, one of the most water-intensive demand is need for water for hygienic and sanitary purposes, especially in production buildings with high degree of soiling work. The paper presents the study of hot water (DHW) consumption and its profile for sanitary and hygienic purposes in two production halls. The halls vary in the degree of soiling work, sanitary equipment and numbers of employees. The aim of this article is to define DHW consumption profiles and hourly water-consumption irregularity coefficient applicable in design process of hot water preparation for hygienic purposes in production buildings. The average daily hot water consumption varies significantly and amounts 7 or $16 \mathrm{~m}^{3}$ respectively to both halls. Despite the discrepancy of sanitary equipment and number of workers the hourly water-consumption irregularity coefficients for both halls are in the similar range, about 2 , and daily domestic hot water profiles present typically three main consumption peaks that occur at the end of work shifts.
\end{abstract}

\section{Introduction}

The large-cubage buildings belong to the group in which the level of energy consumption is significant and reaches about $400 \mathrm{kWh} /\left(\mathrm{m}^{2} \cdot\right.$ year) [1]. Beyond the demand of large amount of energy, industrial buildings are characterized of high water consumption, particularly freshwater [2]. In year 2011 industrial plants in Poland itself consumed about $651.6 \mathrm{hm}^{3}$ of water [3]. The publications $[1,4]$ present the examples and calculations of water usage and energy needed to prepare domestic hot water in such buildings. These demands depend on the building purposes, the operating schedule, number of people and sanitary equipment. However the mentioned literature point out the additional difficulty in energy and water usage calculations caused by the discrepancy in guidelines for domestic water calculations and thus problems with the estimation of the real water and energy demand.

However each branch of industry requires an individual approach to the analysis of energy and water consumption $[2,3,5]$ depending on the purposes, for instant:

\footnotetext{
*Corresponding author: edyta.dudkiewicz@pwr.edu.pl
} 
- hygienic/sanitary (cold and DHW),

- fire-fighting, sprinkler installation,

- technological processes,

- production of steam,

- additional purposes (e.g. irrigation/watering/cleaning).

The most water-intensive purposes in production halls are technological processes [5]. In production buildings with high degree of soiling work and a large amount of workers, where water is used for hygienic and sanitary purposes, domestic hot water (DHW) is also accounted as large percentage of water consumption and generates significant energy consumption. In such buildings the showers and washbasins are basic equipment. Thus the water consumption depends on the number and type of hygienic equipment and sanitary facilities, degree of soiling work, type of work and sex of workers [6, 7].

Acquisition of knowledge about the amount and profile of water consumption and their irregularity allows to evaluate the development of technology in water supply networks and installations as well as water supply and sewage systems $[2,5,8]$. Additionally water load pattern gives the possibility to understand and forecast the daily sanitary needs of workers. Further the forecast can be integrated with a control strategy to optimize the energy costs of DHW preparation and possibility of implementation of renewables and waste sources [7]. Furthermore it is also worth to emphasize the fact that, especially from the engineering point of view, neglecting knowledge concerning the characteristics of hot water consumption in a building would result in oversizing or undersizing the installation or the whole system and thus problems with exploitation $[6,9,10]$. Additionally wrongly sized installation may cause an occurrence of too low or too high velocities of the flow and thus may have negative effect on the system operation $[11,12]$. Too low velocities may lead to water stagnation in the water network, the occurrence of chemical and biological processes in pipes, the intensive sedimentation on the internal surfaces of water pipes and the development of biofilms [13]. The occurrence of biofilm, temperature increase and water stagnation are the main reasons of occurrence and multiplication of Legionella pneumophila [15, 18]. All these aforementioned factors have a negative effect on decreasing water quality which can be dangerous for human life.

In all buildings, also in the industrial halls, water consumption is characterised by variability over the time. Concept of annual, seasonal, monthly, weekly, daily, hourly and second fluctuations can be distinguished $[15,16]$. This inequality of water consumption influences on various processes and issues aforementioned.

Reviewing the literature in the field of hot water consumption profiles and its irregularity it was found that researchers have been widely studied domestic hot water consumption profiles in residential buildings or public buildings such as hospitals, hotels or office buildings [10, 16-18]. However the subject related to production halls has been omitted and in the literature there is a the lack of the described research in such buildings. The daily hot water demand profiles have an inevitable and crucial influence on hot water system design $[18,19]$ therefore this issue related to production halls is the main goal of this paper.

The study presents the results of domestic hot water consumption research for sanitary purposes in two production buildings with different degree of soiling work. The aim of this study is to analyse daily changes in water consumption in industrial halls and investigation the irregularity coefficients of hourly water consumption.

\section{Description of measurements}

The measurements of the hot water consumption were carried out in two production halls with different demand of hot water, degrees of soiling work and sanitary equipment, amount of workers and their sex. The halls are localized on Lower Silesia region in Poland. 
The production hall with the high degree of soiling works will be referred as the industrial hall no. 1 in the next part of this paper. The measurements were carried out over 30 days in October and November in 2017. The industrial hall consists of few departments with sanitary units in each of them. People work on 3 shifts, however on each shift different number of people is working. Total number of workers is 235 . The biggest group of people work on first shift, from 6 am to $2 \mathrm{pm}$. All workers are male. The work in the hall is organized 5 days per week, from Monday to Friday. Due to high soiling work the bathrooms are equipped with 24 showers and 22 washbasins.

The second hall will be referred in this paper as the industrial hall no. 2 . The work in the hall is of low soiling potential. The measurements were performed over 3 months from March to June in 2018. People work in the hall in a three-shift system, six days per week. About 350 people work during the morning shift from 6 am to $2 \mathrm{pm}$, about 250 people during the day shift from $2 \mathrm{pm}$ to $10 \mathrm{pm}$, and about 100 people during the night shift from $10 \mathrm{pm}$ to $6 \mathrm{am}$. Most workers in the industrial hall no. 2 are women. The bathrooms are equipped in 22 washbasins and no showers are installed.

The Table 1 presents summarised information about the characteristics of the industrial halls where the measurements were conducted.

To measure water flow rate and water velocity the portable ultrasonic flow meter (PORTAFLOW C) was installed on the pipe delivering water to hot water tank (the storage unit). Data was sampled and archived every 10 seconds.

\section{Results of the research}

The significant parameter in water installation design and assessment of water consumption in buildings is the average daily water consumption. The average daily hot water consumption in industrial hall no. 1 was $16 \mathrm{~m}^{3}$ while average daily hot water consumption per person equals 681 . The average temperature in hot water tank was $46^{\circ} \mathrm{C}$. This value is very close to the temperature reported in many publications [20]. The calculated value of the water consumption for one bath in hall no. 1 is greater than the described in literature value of 501 per person and temperature $35^{\circ} \mathrm{C}$ [20].

The hot water consumption in industrial hall no.2 also varied. Daily values fluctuated between $1.9 \mathrm{~m}^{3}$ in Saturday to $7.3 \mathrm{~m}^{3}$ during a week. Average daily hot water consumption per person was estimated as 8.51 what is more than $7 \mathrm{l} /$ person and day recommended in guidelines and handbooks, e.g. [21]. However it has to be highlighted that the recommended value assumes tap water temperature of $55^{\circ} \mathrm{C}$ while the hot water temperature of the measuring period was $45^{\circ} \mathrm{C}$. The average weekly hot water consumption in production hall no. 2 was almost half lower than in hall no. 1 and equalled $45 \mathrm{~m}^{3}$.

The second important factor in designing process of hot water systems is the energy demand for hot water preparation. It is crucial when implementation of renewable sources of energy are considered, especially utilization of solar collectors [7, 22]. It is strongly related to the number of people using hot water and the schedule of the usage. Table 1 presents the average amount of water consumption and estimated energy demand for shifts, day, week and a month. Monthly heat demand for production of hot tap water was calculated from the formula:

$$
Q_{h t w}=\left[(x / 7) \cdot l_{d} \cdot m_{d} \cdot c_{w} \cdot\left(t_{h w}-t_{c w}\right) \cdot 10^{-3}\right] / 3600
$$

where: $l_{d}$ - number of days in a month (-), $m_{d}$ - daily demand of the hot tap water (kg/day), $c_{w}$ - specific heat of water $(\mathrm{kJ} /(\mathrm{kg} \cdot \mathrm{K})), t_{h w}$ - temperature in the hot water tank $\left({ }^{\circ} \mathrm{C}\right)$, $t_{c w}$ - temperature of the cold water $\left({ }^{\circ} \mathrm{C}\right)$. The $x / 7$ coefficient in the formula (1) was introduced to take into account the water draw-off over 5 or 6 days per week in both halls. 
Table 1. The data related to working conditions, water and energy consumption in both halls.

\begin{tabular}{|c|c|c|}
\hline & Industrial hall no. 1 & Industrial hall no. 2 \\
\hline Number of work shifts & 3 & 3 \\
\hline Total amount of people per day & 235 & 750 \\
\hline Working days per week & 5 & 6 \\
\hline Degrees of soiling work & high soiling & low soiling \\
\hline $\begin{array}{c}\text { Sanitary equipment (of hot water): } \\
\text { Shower } \\
-\quad \text { Washbasin }\end{array}$ & Yes & No \\
\cline { 2 - 3 } & Yes & Yes \\
\hline Average temperature in hot water tank $\left({ }^{\circ} \mathrm{C}\right)$ & 46 & 45 \\
\hline Average daily hot water consumption $\mathrm{G}_{\mathrm{d}}\left(\mathrm{m}^{3}\right)$ & 16 & 7 \\
\hline Daily energy demand $(\mathrm{kWh})$ & 763 & 297 \\
\hline Energy demand per person $(\mathrm{Wh} /$ person) & 3250 & 896 \\
\hline $\begin{array}{c}\text { Average daily hot water consumption } \\
(1 / \text { person })\end{array}$ & 68 & 45 \\
\hline Average weekly DHW consumption $\left(\mathrm{m}^{3}\right)$ & 80 & 2095 \\
\hline Weekly energy demand $(\mathrm{kWh})$ & 3818 & 7642 \\
\hline $\begin{array}{c}\text { Monthly energy demand DHW purposes } \\
(\mathrm{kWh})\end{array}$ & 16361 & \\
\hline
\end{tabular}

\subsection{Hot water consumption profiles}

In generally in production building hot water demand has periodical peaks at the end of each work shift when showers and washbasins are used. Duration of draw-off periods lasts for about 30 minutes. The periods of installation usage are dependent on the number of working shifts and working/holiday days during a year. The general rule in the DHW designing process assumes the constant value of hot water demand during the year [7]. Fig. 1 presents profile of dynamic of hot water consumption for hall no. 2 during seven days. As is shown distribution of hot water consumption is very similar in weekdays.

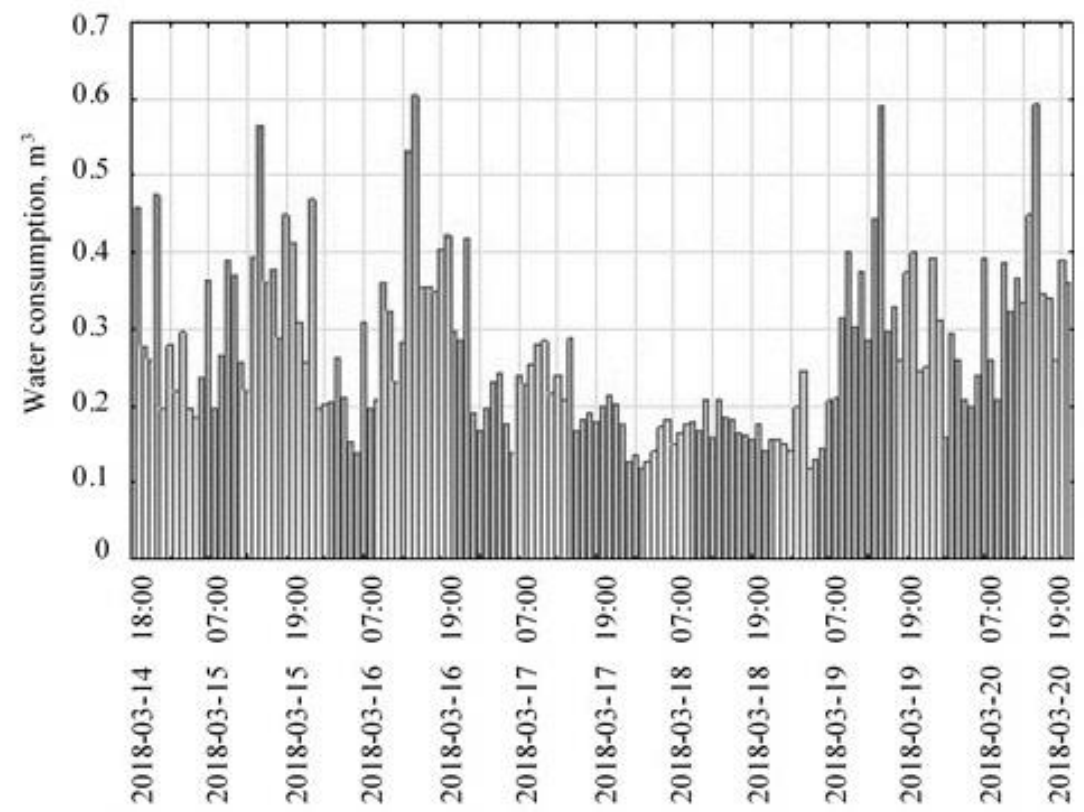

Fig. 1. Profile of dynamic of hot water consumption for hall no. 2 for one week [23]. 
The studied industrial halls have different amount of water consumption, but as shown in Fig. 2 daily water load patterns are quite similar. A considerably larger water demand is observed after the first shift between 6 am to 2 pm during the weekdays. The peak of water consumption occurs at $2 \mathrm{pm}$ and hourly domestic water consumption fluctuates between $8.4-8.9 \%$ of daily water consumption. After the second shift also the second peak is observed - in both halls the percentage of hourly domestic water consumption is in a range of 5.6-6.1\%. Analysing Fig. 2, in hall no. 1 with a high soiling work, also the third peak, after night shift at 6 am is visible. During the remaining working hours discrepancies in hourly domestic water consumption between two industrial halls are substantial, but still, the highest consumption for both buildings is after the first shift. The actual distributions of water consumption based on the measurements in both halls are significantly different from the theoretical ones described in the literature [23, 24]. Better understanding of the reductions in average daily peak hour water demand impacts on design process.

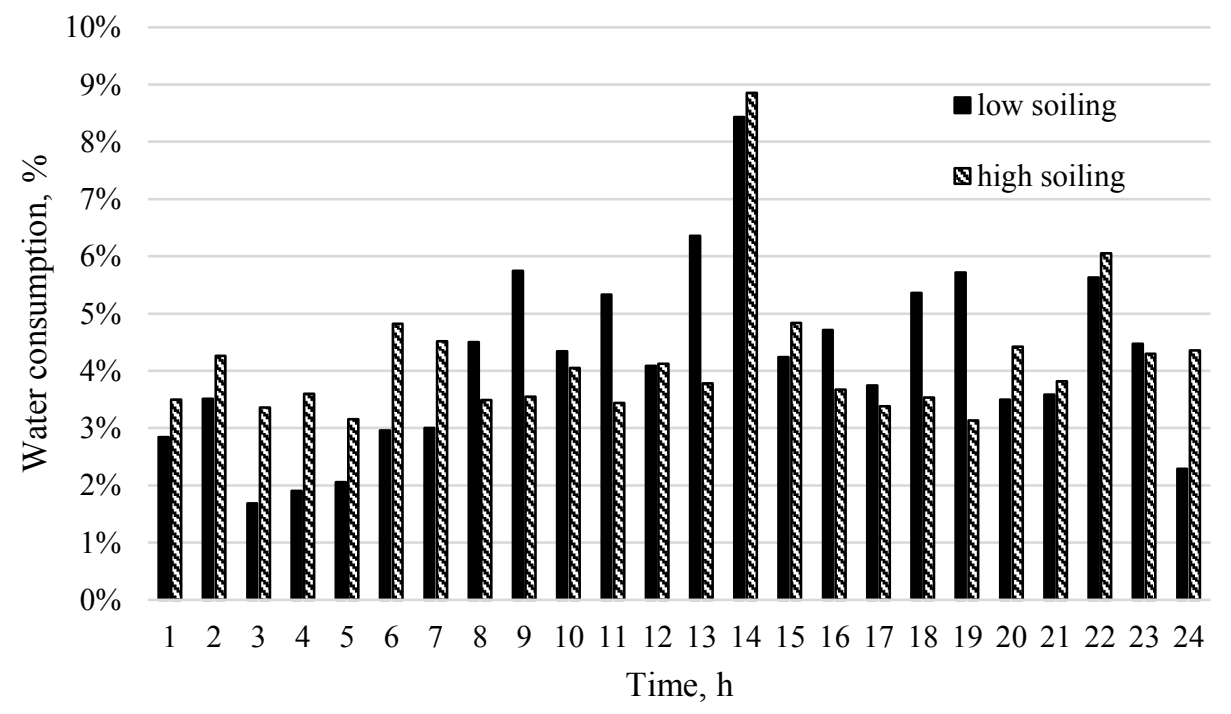

Fig. 2. Profile of percentage distribution of hot water consumption for both halls (right - industrial hall no. 1, left - industrial hall no. 2).

Analysing the hot water consumption profiles the conclusion arises that the consumption of hot water is irregular throughout the day [14]. Irregularity of water consumption in buildings is characterized by various coefficients. One of the most important is the hourly water irregularity coefficient $\mathrm{N}_{\mathrm{h}}$. It is defined by the quotient of maximum hourly demand $G_{\text {hmax }}$ and average hourly water demand $G_{\text {hav }}$ :

$$
N_{h}=G_{\text {hax }} / G_{\text {hav }}
$$

The coefficient is dimensionless and its value defines upper limits of variability ranges of hourly water consumption. The hourly water-consumption irregularity coefficients for both halls are in similar range and oscillate around the value of 2. For all measured days the irregularity coefficients fluctuate between 1.74 and 2.36 for hall no. 1, and 1.24 and 2.56 for hall no. 2.

In residential buildings the value of hourly water-consumption irregularity coefficients decrease with the rising number of residents [9]. This is due to the fact that for all residential buildings, the same amount of hot water consumption per person is assumed. Whereas in production halls this value depends on equipment and number of sanitary facilities, and rises 
with the degree of soiling work. It was estimated, that for hall no. 1 the average daily hot water consumption per person is 681 and for hall no. $2-8.51$. In production halls the values of hourly water-consumption irregularity coefficients decrease with the increase of the water consumption in the buildings during the day. Fig. 3 presents the relationship between hourly water-consumption irregularity coefficients and daily water demands $G_{d}$. On the left hand site the relationship for the hall no. 2 is presented, on the right - for hall no. 1. Following the measurements, the equations describing the relationship between the daily demand of water and hourly water consumption for particular hall were derived and presented in Fig. 3. The formulas are as follow:

- $\quad$ for industrial hall no. 1:

$$
N_{h}{ }^{l}=0,44 G_{d}{ }^{l}+1,315
$$

- $\quad$ for industrial hall no. 2:

$$
N_{h}^{2}=-0,079 G_{d}^{2}+1,9076
$$

The values of the hourly irregularity coefficient of hot water is higher than the hourly cold water irregularity coefficient, which in turn is higher than the coefficient of hourly irregularity distribution of the total water (together cold and hot):

$$
N_{h}{ }^{D H W}>N_{h}{ }^{c w}>N_{h}^{t w}
$$

It is crucial to pay particular attention for above relationship (5) when dimensioning the water supply installations. It happens that designers accept the value of the irregularity coefficient, not paying the proper attention to which water it is dedicated.

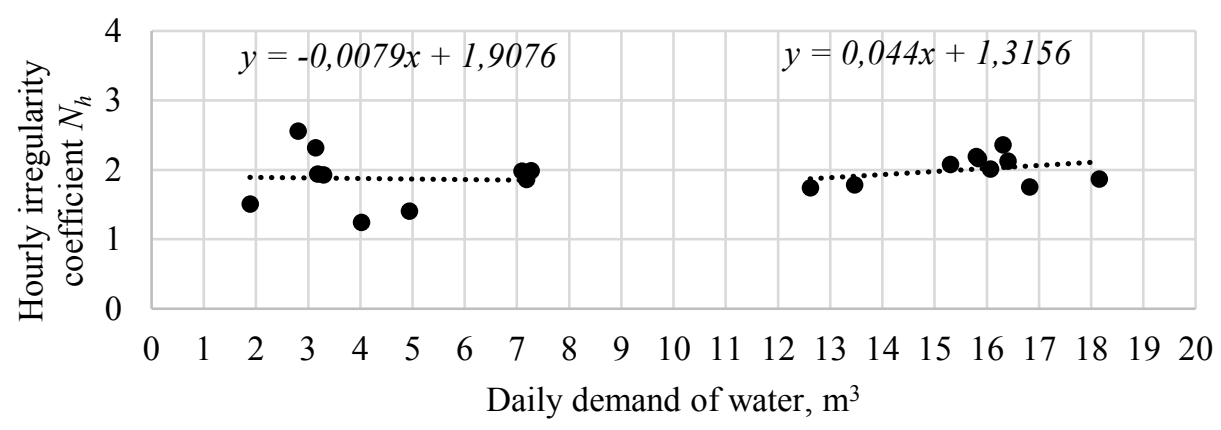

Fig. 3. The functional dependence of daily demand of water and hourly water consumption irregularity coefficient $N_{h}$ (left- for industrial hall no.2, right- states for industrial hall no. 1).

\subsection{Energy consumption}

In the technical design process, on the stage of the sizing the DHW system, the assumption of water storage (water accumulation) option is on the great importance. Characterization of domestic hot water profiles would allow for designing innovative control strategies for DHW systems [16]. The Table 2 produces an overall relationship in methodological approach between the heat load of the heat exchanger and the volume of the storage tank [19]. From the engineering point of view the relation between the value of heat load reduction factor $\psi$ and accumulation coefficient $\varphi$ plays the crucial role. 
Table 2. Dependence between the heat load of heat exchanger and volume of water storage tank.

\begin{tabular}{|c|c|c|}
\hline Accumulation & Heat load of heat exchanger & Volume of water storage tank \\
\hline Non-accumulation & $Q_{h \max }{ }^{*}$ & $V=0$ \\
\hline Partial accumulation & $\Psi \cdot Q_{h \max }$ & $V=\varphi \cdot V_{z}$ \\
\hline Full-accumulation & $Q_{h}{ }^{* *}$ & $V=V_{z}$ \\
\hline
\end{tabular}

Volume of water storage tank $V_{z}$ is calculated following on standardized values of hot water demand per person and day (1/person-day) or energy consumption (Wh) during the utilization of the sanitary equipment. Following the literature energy consumption for the washbasin and shower varies between 500 and 870 (Wh), and from 1450 to 2300 (Wh) respectively. Energy demand per person in industrial hall no.1 was calculated to $3250(\mathrm{Wh} /$ person) and $396(\mathrm{Wh} /$ person) in hall no. 2 (see Table 1). Whereas the value for hall no. 2 is in the recommended range aforementioned, the energy demand for the hall no. 1 with high soiling work is significant higher.

\section{Conclusion}

The acquisition of knowledge about the ranges of water consumption of each equipment and person, consumption profiles and peak times occurrence is helpful especially at early stage of the technical design, namely for selection of a measuring device (flow meters), sizing hot water preparation system, pipe dimensioning, defining the volume of the storage tank, etc. Furthermore the domestic hot water consumption is an important part of the building energy demand. The forecast of consumed DHW volume allows to control and reduce the costs of energy needed for hot water preparation.

The paper presented inequality of water consumption for hygienic and sanitary purposes calculated on the basis of the measurements conducted in two production halls located in Poland. Despite the substantial differences in the operating parameters of the considered buildings, the distribution profiles of hot water consumption are similar. The halls differ with the sanitary equipment, the degree of soiling work, number and sex of workers. However, the three-shift work schedule, common for both halls, was the reason of the occurrence of the typical water peaks in the water consumption profiles after each completed shift.

Despite the discrepancy of sanitary equipment and number of workers the hourly water-consumption irregularity coefficients for both halls are in the similar range. In our study this value oscillates around 2. Due to the lack of information in the literature about values of the hourly water-consumption irregularity coefficient $N_{h}$ for sanitary purposes in production halls, and following the results of the research, the authors assume that the aforementioned value could be suitable also for other industrial halls.

The work was partially financed by The Faculty of Environmental Engineering, Wroclaw University of Science and Technology, Poland. Ref. no. 0401/0055/18.

\section{References}

1. Financing of buildings' energy efficiency improvement in Poland, BPIE (2016)

2. E. Ahmetović, I. E. Grossmann, AIChE Journ. 57, 2 (2010)

3. J. Wojdalski, B. Drózdz, J. Piechocki, Polish J. Chem. Technol. 15, 2 (2013)

4. M. Małetka, M. Laska, E3S Web of Conferences, 22 (2017)

5. A. Reynaud, Environ. Resour. Econ. 25 (2003)

6. E. Dudkiewicz, A. Zabnieńska-Góra, E3S Web of Conferences, 45 (2018) 
7. N. Fidorów-Kaprawy, E. Dudkiewicz, E3S Web Conf. 22 (2017)

8. M. C. Amiri, H. Mohammadifard, G. Ghaffari, AIP Conf. Proc. 1758 (2016)

9. P. Podwójci, Inżynieria Ekol. 26 (2011)

10. E. J. Pieterse-Quirijns, A. H. Van Loon, H. Beverloo, Procedia Eng. 70 (2014)

11. M. Świderska-Bróż, M. Wolska, Ochr. Środowiska 26, 4 (2004)

12. B. Toczyłowska, Technologia Wody 1, 45 (2016)

13. N. Lin, H. Arabnejad, S. A. Shirazi, B. S. McLaury, Powder Technol. 336 (2018)

14. L. Zhang, J. Xia, J. E. Thorsen, O. Gudmundsson, S. Svendsen, Energy, 116 (2016)

15. R. Pasela, M. Goraczko, Rocz. Ochr. Sr. 15, 1 (2013)

16. E. Fuentes, L. Arce, J. Salom, Renew. Sustain. Energy Rev. 81 (2018)

17. J. García-Sanz-Calcedo, F. López-Rodriguez, T. Yusaf, Energies 10, 4 (2017)

18. R. Rankin, P. G. Rousseau, Energy Convers. Manag. 47 (2006)

19. B. Nowak, G. Bartnicki, COW, 3 (2004)

20. Compedium of knowledge Recknagel ER, OmniScala (2008)

21. A guide to the designer of boiler rooms with innovative solutions from Brötje (2014)

22. J. C. Evarts, L. G., Swan, Energy Build. 58 (2013)

23. E. Dudkiewicz, A. Żabnieńska-Góra, Rynek Instal. 7/8 (2018)

24. S. Mańkowski, Designing Domestic Hot Water Installations (Arkady, 1981) 